\title{
DIVERSITY OF MOSQUITOES COLLECTED FROM THE SOUTHERN AREAS OF KHYBER PAKHTUNKHWA -PAKISTAN
}

\author{
Khan Niaz Khan ${ }^{1}$, Muhammad $\mathrm{Ali}^{2}$, Muhammad Zahid ${ }^{3}$, Wasim $\mathrm{Ahmad}^{4}$
}

ABSTRACT:

OBJECTIVES:

The objective of the study was to assess the diversity of mosquitoes in various towns of the southern belt of KPK.

\section{METHODOLOGY:}

This was a descriptive study that was conducted in numerous towns of Western belt of Khyber Pakhtunkhwa. The study areas were Darra Adam Khel, District Kohat, District Karak, District Banu, District D.I. Khan and newly merged districts Mir Ali and Miranshah. From each study site, the samples were collected randomly. The sample collection was done through survey and area visits whereas; the identification process was done in a parasitology laboratory of Hayatabad-Peshawar. Sampling was done from June 2016 to May 2017.

\section{RESULTS:}

A total of 2150 adult mosquitoes were gathered and collected from 42 different locations of the southern belt of KPK and were identified. Based on their identification, 5 genera of the mosquito es were recognized which were Culex, Anopheles, Psorophora, Aedes and Uranotenia. Culex was found to be most dominant in all the visited areas with a percentage of 12.65 in Miranshah followed by 11.81 in Mirali, 7.16 in Karak, 6.88 in Darra Adam Khel, 6.69 in D.I.Khan, 6.41 in Kohat and 5.11 in Bannu respectively. The results of our findings also revealed the presence of Culex genera in all the habitats and remained the dominant genera among the others followed by Anopheles and Psorophora. Aedes was found in the habitat of plants and grasses etc. whereas Uranotenia was found in marsh/swampy areas as well as in plants/grasses habitat only.

\section{CONCLUSION:}

The outcomes reveal that a climate shifting and extensive urbanization process is enforcing the diversity of mosquitos' fauna in the southern belt of KPK.

KEYWORDS: Diversity, Fauna, Mosquitoes, Anopheles, Culex, Aedes

How to cite this article:

Khan KN, Ali M, Zahid M, Ahmad W. Diversity of Mosquitoes Collected from the Southern Areas of Khyber Pakhtunkhwa-Pakistan.

J Gandhara Med Dent Sci. 2022;9(1): 3-8

https://doi.org/10.37762/jgmds.9-1.170

\section{Correspondence}

${ }^{4}$ Wasim Ahmad, Assistant professor, School of Health

Sciences, Peshawar.

(1): $\quad+92-333-5534847$

凶: vazim4847@gmail.com

'Senior Lecturer, Edwardes College, Peshawar.

${ }^{2}$ Associate Professor, Bacha Khan University, Peshawar

${ }^{3}$ Assistant Professor, Islamia College, Peshawar

\section{INTRODUCTION:}

Numerous deadly diseases including Dengue, Malaria, Chikungunya and Zika virus are caused by few medically important arthropods known as mosquitos. The annual death ratio due to lethality of this vector is around one million ${ }^{1}$. There are some 3541 reported species of mosquitoes around the globe. These species belong to 42 genera $^{2}$. As far as Pakistan is concerned, the reported species are 134, which fit in Culicinae and Anopheline sub-families ${ }^{3}$. The well-known human malaria vector has its place in genus Anophele whereas the vector for bird malaria belongs to genus Culex. The role of mosquitoes in the food chain of numerous eco-systems is well established ${ }^{4}$. Vector borne diseases are threatening the lives of people in developing countries like Pakistan. Here in Pakistan, the climatic changes are encouraging the 
chances of mosquito borne diseases ${ }^{5}$. In Lahore, there were 11283 reported cases of Dengue fever in year $2012^{6}$. More or less 2179 cases of Dengue fever were found positive in a recent outburst in KPK. The South Asian countries' climatic change has worsened the prevalence of mosquito borne diseases in the area ${ }^{7,8}$. Furthermore, numerous other factors including rainfall, temperature, humidity etc. are in favor of an increase in population of mosquitoes with an enhanced survival $^{9,10}$. Various studies have been conducted throughout Pakistan to report the diversity of mosquitoes in different areas ${ }^{11-15}$. In the year 2013, a study was conducted in Lahore on bio-diversity of mosquitoes with its climatic scenario. The reported species were Anopheles stephensi, Aedes aegypti, Culex quinquefasciatus and Anopheles subpictus. The mosquito fauna of Pakistan was powered by the addition of three Culex and one Anopheles species during 1934 to $1971^{16}$. In the year 1977, 30 species were reported from Changa Manga, Lahore ${ }^{17}$. In 1993, numerous mosquitos' species were reported from Peshawar and its neighboring areas with their relative abundance ${ }^{18}$. The breeding of the mosquitoes can be seen in vicinities where water remains stagnant in pools or ditches etc., near holes of the trees, pools containing leafy debris, forest area and blocked gutters etc. Adult mosquitoes remain throughout their life near larval habitations. Plant nectar and juices remain the major source for their feeding. The female mosquitoes also nourish on juices but they need a blood diet for developing their eggs. The study was aimed to assess the diversity of numerous species of mosquitoes in varying habitats of southern KPK districts.

\section{METHODOLOGY:}

This was a descriptive study that was conducted in numerous towns of Western belt of Khyber Pakhtunkhwa to compare population dynamics and to establish a baseline data on diversity of mosquitos' genera. The localities included were Darra Adam Khel, District Kohat, District Karak, District Banu, District D.I.Khan and newly merged districts Mir Ali and Miranshah. From each study site, the samples were collected randomly. The sample collection was done through survey and area visits whereas; the identification process was done in a parasitology laboratory of HayatabadPeshawar. Sampling was done from June 2016 to May 2017. Special codes were allotted for various mosquitoes and tagged. A total of 42 localities (6 from each area) were assessed in which, some localities were of habitats. These habitats were: toilets, muddy or wet areas, plants, trenches, animal hutches and houses etc. Various habitats were observed with naked eye for the determination of prevalence of mosquitoes. The mosquitoes were collected from the specified localities at the ground level earlier in morning and evening time. Sweepers and battery-operated aspirators were used for the collection of adult mosquitoes. The collected samples were shifted to plastic jars that were covered with nets for further identification process in the parasitology lab of Hayatabad-Peshawar. The samples were specified and tagged properly and their respective geographical locations were mentioned. To kill the mosquitoes, they were sucked from the plastic jars with the help of an aspirator and were then shifted to conical jars that were kept airtight and contained a cotton pad immersed in chloroform. All the adult mosquitoes were killed within 2 to 3 minutes. The mosquitoes were preserved in test tubes that contained a tiny quantity of silica gel for preservation. The identification of the mosquitoes was done using "Standard Taxonomic Keys", The ethics committee of the Bacha Khan University, Charsadda approved the study. By using the following formula, relative abundance was determined. Relative abundance $=\mathrm{n} /$ total no of species $\mathrm{x} 100$ In the above formula, $\mathrm{n}$ is the number of mosquitoes divided by the total number of mosquitoes gathered from the localities multiplied by 100 . A value of more than $10 \%$ of relative abundance was considered as dominant species whereas from 3 to $10 \%$ were termed as subdominant species.

\section{RESULTS:}

A total of 2150 adult mosquitoes were gathered and collected from 42 different sites of the southern belt of KPK both from urban and rural areas of the selected districts and were identified.

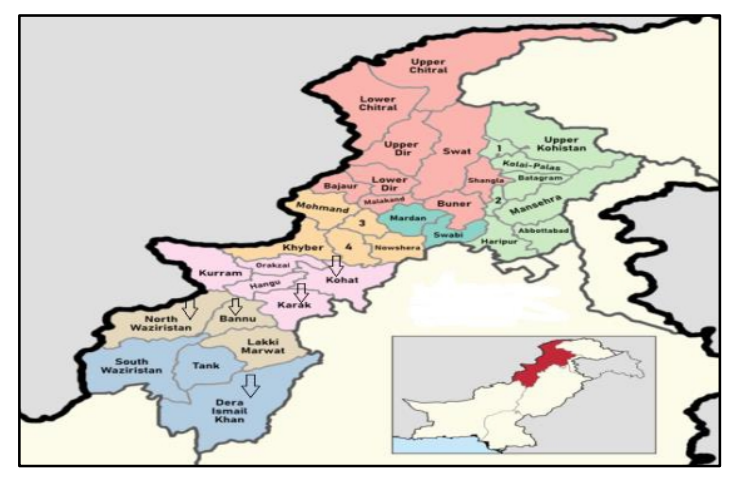

Figure 1: Western Belt of KPK and Sampling Areas Shown with Arrows 
Table 1: Geo-Coordinates of Sampling Areas

\begin{tabular}{|c|c|c|c|}
\hline No & Sampling Area & Geographical Region & Geo-Coordinates \\
\hline 1 & Darra Adam Khel & \multirow{7}{*}{ Southern KPK } & $\begin{array}{l}33.684^{\circ} \mathrm{N} \\
71.516^{\circ} \mathrm{E} \\
\end{array}$ \\
\hline 2 & Kohat & & $\begin{array}{l}33^{\circ} 19^{\prime} 60.00^{\prime \prime} \mathrm{N} \\
71^{\circ} 09^{\prime} 60.00^{\prime \prime} \mathrm{E}\end{array}$ \\
\hline 3 & Karak & & $\begin{array}{l}33^{\circ} 6^{\prime} 54.9684^{\prime \prime} \mathrm{N} \\
71^{\circ} 5^{\prime} 43.9260^{\prime \prime} \mathrm{E}\end{array}$ \\
\hline 4 & Bannu & & $\begin{array}{l}32^{\circ} 59^{\prime} 9.9996^{\prime \prime} \mathrm{N} \\
70^{\circ} 36^{\prime} 14.9904^{\prime \prime} \mathrm{E}\end{array}$ \\
\hline 5 & D.I.Khan & & $\begin{array}{l}31^{\circ} 49^{\prime} 53.3352^{\prime \prime} \mathrm{N} \\
31^{\circ} 49^{\prime} 53.3352^{\prime \prime} \mathrm{N}\end{array}$ \\
\hline 6 & Mirali & & $\begin{array}{l}32.9700^{\circ} \mathrm{N} \\
70.2776^{\circ} \mathrm{E}\end{array}$ \\
\hline 7 & Miranshah & & $\begin{array}{l}33.00250^{\circ} \mathrm{N} \\
70.06889^{\circ} \mathrm{E}\end{array}$ \\
\hline
\end{tabular}

Table 2: Prevalence of Different Genera of Mosquitoes' in Southern Belt of KPK

\begin{tabular}{|c|c|c|c|c|c|c|c|c|c|c|c|c|c|c|c|}
\hline Genus & Darra & $\%$ & Kohat & $\%$ & Karak & $\%$ & Bannu & $\%$ & $\begin{array}{l}\text { D.I } \\
\text { Khan }\end{array}$ & $\%$ & Mirali & $\%$ & $\begin{array}{l}\text { Miran } \\
\text { Shah }\end{array}$ & $\%$ & Total \\
\hline Culex & 148 & 6.88 & 138 & 6.41 & 154 & 7.16 & 110 & 5.11 & 144 & 6.69 & 254 & 11.81 & 272 & 12.65 & 1220 \\
\hline Anopheles & 21 & 0.97 & 27 & 1.25 & 40 & 1.86 & 68 & 0.03 & 82 & 3.81 & 74 & 3.44 & 78 & 3.62 & 390 \\
\hline Aedes & 4 & 0.18 & 19 & 0.88 & 44 & 2.04 & 76 & 3.53 & 98 & 4.55 & 101 & 4.69 & 121 & 5.62 & 463 \\
\hline Psorophora & 4 & 0.18 & 8 & 0.37 & 12 & 0.55 & 4 & 0.18 & 14 & 0.65 & 6 & 0.27 & 4 & 0.18 & 52 \\
\hline Uranotenia & 2 & 0.09 & 0 & 0 & 4 & 0.18 & 1 & 0.04 & 5 & 0.23 & 5 & 0.23 & 8 & 0.37 & 25 \\
\hline Total & & & & & & & & & & & & & & & 2150 \\
\hline
\end{tabular}

Table 3: Different Genera of Mosquitoes' Collected in Numerous Habitats in Southern Belt of KPK

\begin{tabular}{|c|c|c|c|c|c|c|c|c|c|c|c|c|c|}
\hline \multirow[t]{2}{*}{ Genus } & \multicolumn{2}{|c|}{$\begin{array}{l}\text { Marsh/Swamp } \\
\text { areas }\end{array}$} & \multicolumn{2}{|c|}{ Toilets } & \multicolumn{2}{|c|}{ Plants/Grasses } & \multicolumn{2}{|c|}{$\begin{array}{l}\text { Animal } \\
\text { Hutches }\end{array}$} & \multicolumn{2}{|c|}{ Treenches } & \multicolumn{2}{|c|}{ House/Comtainers } & \multirow[t]{2}{*}{ Total } \\
\hline & $(n=)$ & $\%$ & $(\mathrm{n}=)$ & $\%$ & $(n=)$ & $\%$ & $(n=)$ & $\%$ & $(n=)$ & $\%$ & $(n=)$ & $\%$ & \\
\hline Culex & 194 & 30.5 & 424 & 76.25 & 180 & 40.17 & 154 & 100 & 88 & 100 & 180 & 67.16 & 1220 \\
\hline Anopheles & 204 & 32.07 & 54 & 9.71 & 44 & 9.82 & 0 & 0 & 0 & 0 & 88 & 32.83 & 390 \\
\hline Aedes & 218 & 34.27 & 78 & 14.02 & 167 & 37.27 & 0 & 0 & 0 & 0 & 0 & 0 & 463 \\
\hline Psorophora & 0 & 0 & 0 & 0 & 25 & 5.58 & 0 & 0 & 0 & 0 & 0 & 0 & 25 \\
\hline Uranotenia & 20 & 3.14 & 0 & 0 & 32 & 7.14 & 0 & 0 & 0 & 0 & 0 & 0 & 52 \\
\hline Total & 636 & & 556 & & 448 & & 154 & & 88 & & 268 & & 2150 \\
\hline
\end{tabular}

Table 4: Details of the Species Collected from Different Genera

\begin{tabular}{|c|c|c|}
\hline No & Genera & Species \\
\hline 1 & \multirow{6}{*}{ Culex } & Cx. pseudovishnui (U) \\
\hline 2 & & Cx. pseudovishnui (R) \\
\hline 3 & & Cx. quinquefaciatus (U) \\
\hline 4 & & Cx. quinquefaciatus (R) \\
\hline 5 & & Cx. tritaeniorhynchus (U) \\
\hline 6 & & Cx. tritaeniorhynchus (R) \\
\hline 7 & \multirow{4}{*}{ Anopheles } & An. subpictus (U) \\
\hline 8 & & An. subpictus (R) \\
\hline 9 & & An. stephensi (U) \\
\hline 10 & & An. stephensi (R) \\
\hline 11 & \multirow{4}{*}{ Aedes } & Ae. aegpyti (U) \\
\hline 12 & & Ae. aegpyti (R) \\
\hline 13 & & Ae. albopictus (U) \\
\hline 14 & & Ae. albopictus (R) \\
\hline
\end{tabular}

\section{DISCUSSION:}

In this study, overall, 14 species belonging to 3 different genera (Culex, 6 species, Aedes, 4 and Anopheles, 4 species) were identified that were collected from both urban and rural areas of the study scenario. The other collected species remained unidentified. The identified species were: $\mathrm{Cx}$. pseudovishnui (U), Cx. pseudovishnui (R), Cx. quinquefaciatus (U), Cx. quinquefaciatus (R), $\mathrm{Cx}$. tritaeniorhynchus (U), Cx. tritaeniorhynchus (R), An. subpictus, (U), An. subpictus (R), An. stephensi (U), An. stephensi (R), Ae. aegpyti (U), Ae. aegpyti (R), Ae. albopictus (U) and Ae. albopictus (R) respectively. In a study that was conducted in Murree-Pakistan, 13 species were mainly identified that were collected from the various localities of the Murree. The most abundant species were Aedes aegypti, Armigerus obturbans 
and $\mathrm{Cx}$. fuscitarsis respectively followed by $\mathrm{Cx}$. nilgiricus and $\mathrm{Cx}$. vagans. The all reported species in Murree were the same as reported by Barruad (1934) excepting one type that was Cx. raptor. The aforementioned study revealed all the collected species majorly in the month of July to November whereas April was the month in which, minimum number of species were collected. The months of January, February, March and December were the ones in which no sampling was done because of rain and snowfall. The mosquitoes' fauna of various districts of Pakistan is reported in various research studies. In a study conducted in Lahore, 29 species of mosquitoes were reported ${ }^{19}$. In another study in the same city, the mosquitoes' fauna was reported to be 31 from seven different genera ${ }^{20}$. The outcomes of a study done in Faisalabad displayed 36.8\% existence of Culex genera and $32.1 \%$ existence of Anopheles genera ${ }^{8}$. In a report that was published from Thailand, revealed the dominant existence of Culex species in all the collected mosquitoes' species ${ }^{10}$. In a Tanzanian report, it was stated that the Anopheles species were the dominant among all from traditional flooding rice irrigation ecosystem $^{11}$. A local study that was conducted in Peshawar revealed the presence of Culex and Anopheles species in polluted water trenches in Peshawar $^{12}$. The study revealed the presence of Culex species more or less $99 \%$ from the samples. The outcomes of a Pakistani study that was conducted in Faisalabad shows $26.3 \%$ population of Aedes species in district Faisalabad and its nearby territories ${ }^{6}$. Mukhtar et al, ${ }^{7}$ explored the breeding of mosquitoes in wastewater irrigation where he found three genera Aedes, Culex and Anopheles. Ali and Rashid, $^{12}$ showed the presence of Cx. quinquefasciatus and An. stephensi in polluted water of Palosai stream in district Peshawar. The Aedes species were missing in this water. This research showed that the Aedes species are inhabitants of temporary habitats only. In a study that was conducted in Jhelum-Pakistan ${ }^{21}$, a total of 21 mosquito species containing 365 samples were documented. The species observed were: Culex (9), Anopheles (6), Lutzia (2), Aedes (2), and Armigeres (2). Anopheles stephensi was gathered from 3 habitats, comprising animal shelters, houses and water streams etc. Higher richness/abundance was observed in animal shelters and houses, whereas lower richness/abundance was observed in water streams. Anopheles maculatus was gathered from 2 habitats, comprising animal shelters and water streams. Higher richness/abundance was observed in animal hutches, whereas lower richness/abundance was perceived in water streams. Anopheles annularis collection was done from 3 habitats, containing animal shelters, houses and water streams. Higher richness/abundances were observed from animal shelters and housing areas, whereas the lower richness/abundance was perceived from water rivulets. Anopheles culicifacies and Anopheles tessellatus shared the equal habitations, comprising animal shelters, housing areas and watercourses. Higher richness/abundances of Anopheles culicifacies were observed from animal huts and rivers, whereas lower abundance was observed from housing colonies. Anopheles tessellatus samples were perceived in the same abundances from these habitats. Anopheles theobaldi was gathered from 2 habitats, i.e. animal shacks and inhabited areas. The abundances found from these habitats were equal.Our study revealed that Culex was found to be most dominant in all the visited areas with a percentage of 12.65 in Miranshah followed by 11.81 in Mirali, 7.16 in Karak, 6.88 in Darra Adam Khel, 6.69 in D.I.Khan, 6.41 in Kohat and 5.11 in Bannu respectively. The results of our findings also revealed the presence of Culex genera in all the habitats and remained the dominant genera among the others followed by Anopheles and Psorophora. Aedes was found in the habitat of plants and grasses etc. whereas Uranotenia was found in marsh/swampy areas as well as in plants/grasses habitat only. Our results revealed the presence of Culex genera in ditches $(100 \%)$, in animals' hutches $(100 \%)$, in toilets $(76.25 \%)$, in plants and grasses etc. $(40.17 \%)$ and in marshy and swampy places $(30.50 \%)$. The results show the plants and grasses $(5.58 \%)$ as a positive habitat for Aedes genera while marshy/swampy places (3.14\%) and plants/grasses $(7.14 \%)$ as positive habitat for genera Uranotenia. The positive habitats for genera Psorophora were marshy/swampy places $(34.27 \%)$, toilets $(14.02 \%)$ and plants/grasses (37.27\%) respectively.

\section{CONCLUSION:}

The outcomes of this study reveal that climate shifting and extensive urbanization process is enforcing the diversity of mosquitos' fauna in the southern belt of KPK. The results will be a helping hand in controlling and managing their effective control in the study areas. More studies with larger samples are recommended to cope with the deadly effects of various species of the mosquitoes in the area.

\section{LIMITATIONS:}

Our study is limited to rural and urban areas of a 
few districts of KPK. More areas of the western belt are to be needed to explore for the assessment of mosquitoes profile and diversity by using a larger number of samples in future.

\section{CONFLICT OF INTEREST: None}

FUNDING SOURCES: Faculty development fund for Edwardes College Peshawar by Higher Commission of Pakistan.

\section{REFERENCES:}

1. Ahmad S, Aziz MA, Aftab A, Ullah Z, Ahmad MI, Mustan A. Epidemiology of dengue in Pakistan, present prevalence and guidelines for future control. Int J Mosq Res. 2017;4(6):25-32.

2. Zohaib A, Saqib M, Beck C, Hussain MH, Lowenski S, Lecollinet S, et al. High prevalence of West Nile virus in equines from the two provinces of Pakistan. Epidemiol Infect. 2015;143(9):1931-5.

3. Channa MA, Memon N. Seasonal variation in the prevalence of larvae of aedes aegypti mosquito in district Hyderabad, Sindh, Pakistan. Pure Appl Biol. 2020;9(2):1354-63.

4. Ponce P, Morales D, Argoti A, Cevallos VE. First report of aedes (stegomyia) albopictus (skuse)(diptera:culicidae), the Asian Tiger Mosquito, in Ecuador. J Med Entomol. 2018;55(1):248-9.

5. Wajiha RA, Afridi H, Saeed K. Prevalence of culex, aedes, anopheles and armigers mosquitoes at selected localities of district Peshawar Khyber Pakhtunkhwa Pakistan. Int J Mosq Res. 2017;4(2):128-34.

6. Mawejje HD, Kilama M, Kigozi SP, Musiime AK, Kamya M, Lines J, et al. Impact of seasonality and malaria control interventions on Anopheles density and species composition from three areas of Uganda with differing malaria endemicity. Malar J. 2021;20(1):1-3.

7. Khan J, Khan I, Ghaffar A, Khalid B. Epidemiological trends and risk factors associated with dengue disease in Pakistan (1980-2014): a systematic literature search and analysis. BMC Public Health. 2018;18(1):1-3.

8. Qureshi NA, Fatima H, Afzal M, Khattak AA, Nawaz MA. Occurrence and seasonal variation of human plasmodium infection in Punjab province, Pakistan.
BMC Infect Dis. 2019;19(1):1-3.

9. Virgens TM, Rezende HR, Pinto IS, Falqueto A. Fauna of mosquitoes (diptera: culicidae) in Goytacazes National Forest and surrounding area, State of Espírito Santo, Southeastern Brazil. Biota Neotrop. 2018;18(1).

10. Maquart PO, Sokha C, Boyer S. Mosquito diversity (diptera: culicidae) and medical importance, in a bird sanctuary inside the flooded forest of Prek Toal, Cambodia. J Asia-Pac Entomol. 2021;24(4):1221-7.

11. Rumisha SF, Shayo EH, Mboera LE. Spatio-temporal prevalence of malaria and anaemia in relation to agro-ecosystems in Mvomero district, Tanzania. Malar J. 2019;18(1):1-4.

12. Manzoor F, Shabbir R, Sana M, Nazir S, Khan MA. Determination of species composition of mosquitoes in Lahore, Pakistan. J Arthropod-Borne Dis. 2020;14(1):106.

13. Tyagi V, Goswami D, Dhiman S, Dey D, Rabha B, Chattopadhyay P, et al. Potential malaria vector anopheles minimus (species A) still persisting in North East India. Int $\mathbf{J}$ Mosq Res. 2021;8(3):51-6.

14. Juache-Villagrana AE, De la MoraCovarrubias A, Escárcega-Ávila A, Jiménez-Vega F. Host selection of aedes aegypti and culex quinquefasciatus females in a semi-desert environment in Northern Mexico. Int J Trop Insect Sci. 2021;41:5563.

15. Umeanaeto PU, Asogwa AN, Onyido AE, Irikannu $\mathrm{KC}$, Ifeanyichukwu MO. The parity rate of indoor-resting adult female anopheles and culex mosquitoes and their implication in disease transmission in Nnamdi Azikiwe University female hostels Awka, Southeastern Nigeria. Int J Environ Agric Biotechnol. 2017;2(4):1551-6.

16. Asgarian TS, Moosa-Kazemi SH, Sedaghat MM, Dehghani R, Yaghoobi-Ershadi MR. Fauna and larval habitat characteristics of mosquitoes (diptera: culicidae) in Kashan County, Central Iran, 2019. J ArthropodBorne Dis. 2021;15(1):69-81.

17. Jabeen A, Ansari JA, Ikram A, Khan MA, Tahir MA, Safdar M. A review of the geographical distribution of aedes aegypti, aedes albopictus and other aedes species (diptera: culicidae) in Pakistan. Int J Mosq Res. 2019;6:90-5.

18. Zahir F, Haq I, Haq M, Khan AS, Naushad 
W, Rajab $\mathrm{H}$, et al. Epidemiological characteristics and genetic diversity of clinically isolated dengue vector in Khyber Pakhtunkhwa, Pakistan. Clin Epidemiol Global Health. 2021;12:100863.

19. Wilai P, Ali RS, Saingamsook J, Saeung A, Junkum A, Walton C, et al. Integrated systematics of anopheles subpictus (diptera: culicidae) in the Oriental Region, with emphasis on forms in Thailand and Sulawesi, Indonesia. Acta Trop. 2020;208:105503.
20. Usman K, Rehman HU, Pervaiz K, Khudadad S, Khattak B, Ahmad N. Mosquitoes fauna from Babel Khel district Karak, Khyber Pakhtunkhwa, Pakistan. Int J Mosq Res. 2017;4(3):44-6.

21. Muhammad SR, Muhammad FN, Muhammad N, Muhammad M. Fauna of culex mosquitoes in tehsil Pind Dadan Khan, Jhelum, Punjab, Pakistan. Int J Mosq Res. 2017;4(5):28-31

\section{CONTRIBUTORS}

1. Khan Niaz Khan - Data Acquisition

2. Muhammad Ali - Concept \& Design; Data Analysis/Interpretation; Supervision; Final Approval

3. Muhammad Zahid - Concept \& Design; Data Analysis/Interpretation; Critical Revision; Supervision

4. Wasim Ahmad - Drafting Manuscript; Critical Revision; Supervision

LICENSE: JGMDS publishes its articles under a Creative Commons Attribution Non-Commercial Share-Alike license (CC-BY-NC-SA 4.0) COPYRIGHTS: Authors retain the rights without any restrictions to freely download, print, share and disseminate the article for any lawful purpose. It includes scholarly networks such as Research Gate, Google Scholar, LinkedIn, Academia.edu, Twitter, and other academic or professional networking sites. 